\title{
Chemical Composition and Hepatoprotective Activity of Saponaria officinalis on Paracetamol-Induced Liver Toxicity in Rats
}

\author{
Mallikarjuna Rao Talluri ${ }^{1}$, Veda Priya Gummadi ${ }^{2, *}$, Ganga Rao Battu ${ }^{2}$
}

\section{Mallikarjuna Rao Talluri', Veda Priya Gummadi ${ }^{2, *}$, Ganga Rao Battu²}

\author{
'AnaCipher Clinical Research \\ Organization, Ramanthapur, \\ Hyderabad, Telangana-500013, INDIA. \\ ${ }^{2} A \cup$ College of Pharmaceutical Science, \\ Andhra University, Visakhapatnam, \\ Andhra Pradesh-530003, INDIA. \\ Correspondence

\section{Mr. Veda Priya Gummadi} \\ Research Scholar, A.U College of \\ Pharmaceutical Sciences, \\ Andhra University, Visakhapatnam, \\ Andhra Pradesh-530 003, INDIA. \\ Phone no : +91 8106572834 \\ E-mail: gummadi.veda88@gmail.com

\section{History} \\ - Submission Date: 12-06-2018; \\ - Review completed: 19-07-2018; \\ - Accepted Date: 30-07-2018
}

\section{DOI : 10.5530/pj.2018.6s.24}

\section{Article Available online}

http://www.phcogj.com/v10/i6s

\section{Copyright}

(C) 2018 Phcog.Net. This is an openaccess article distributed under the terms of the Creative Commons Attribution 4.0 International license.

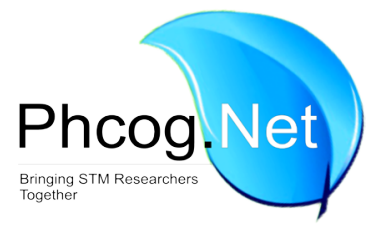

\begin{abstract}
Background: The present day life style causing different illness including liver diseases and different health complications. So, there is a need to identify new chemical entities with more efficiency in the treatment of diseases and less side effects. There were many reports in recent times, about identifying new drugs from different medicinal plants and also precursors for synthesis new bioactive molecules for treating various diseases. Objective: The present study was carried out on root parts (rhizomes) of $S$. officinalis for phytochemical analysis and hepatoprotective activity on Paracetamol-induced liver toxicity. Materials and Methods: The phytochemical analysis was carried out to know biological active compounds in different extracts of $S$. officinalis using standard procedures and quantified the total alkaloid and phenolic contents. Hepatoprotective activity of the $S$. officinalis extracts were carried out by using Paracetamol-induced hepatotoxicity in rats. Results: The phytochemical analysis of $S$. officinalis roots' extracts showed presence of sterols, terpenoids, glycosides, carbohydrates, proteins, flavanoids, alkaloids, phenols, tannins and absence of saponins and oils. The methanolic extract showed more phenolic and alkaloid contents on their quantification. The $S$. officinalis roots extracts are found to be safe at $2000 \mathrm{mg} / \mathrm{kg} \mathrm{b}$. W. in acute toxicity study and showed dose dependent percentage protection on liver toxicity. Methanol extract showed more activity at $500 \mathrm{mg} / \mathrm{kg} \mathrm{b.} \mathrm{W.} \mathrm{and} \mathrm{is} \mathrm{comparable} \mathrm{with} \mathrm{standard} \mathrm{drug} \mathrm{Liv} 52$ on altered liver biomarker enzymes AST (SGOT), ALT (SGPT), ALP, total bilirubin and total protein with percentage protection 56.17\%, 54.53\%, 61.55\% 57.29\% and 53.66\%. Conclusion: The present study results indicates that phytochemical constituent's diversity in S. officinalis and those extracts possess hepatoprotective activity. Further studies are needed and should involve the isolation of pure, biologically active compounds.
\end{abstract}

Key words: Saponaria officinalis, Roots, Paracetamol, Liver, Toxicity.

\section{INTRODUCTION}

Liver is one of the most important organ in the human body, it performs fundamental metabolisms in the body those include homeostasis, carbohydrates, proteins, lipids metabolisms and mainly detoxification. ${ }^{1-2}$ It is important to maintain healthy liver for good health conditions. The present day life style causing different illness including liver diseases. ${ }^{3}$ The drugs using for the present day diseases getting resistant to them and may cause side effects which can lead to iatrogenic diseases. The drugs mainly inducing the vital organs damage in the body like kidney, liver etc. ${ }^{4-6}$ The druginduced liver diseases are more common compared to natural liver diseases around the world. ${ }^{7-8}$ The liver diseases like cirrhosis, cancers, alcoholic liver diseases and non-alcoholic liver diseases are main causes for the liver failure and causing mortality around the world. ${ }^{9}$ The development in modern medicine developed many medication for treatment many diseases including liver diseases. ${ }^{10-12}$ But, these treatments are not satisfactory and as said above on the long-term usage of drugs causing different side effects. ${ }^{13}$ So, there is a need to identify new chemical entities with more efficiency in the treatment of diseases and less side effects.

Traditional medicine is mainly based herbal treatments, which is based on knowledge, skills and practices based on the theories, beliefs and experiences in different indigenous cultures to maintain health. Herbal products that contain parts of plants or other plant materials as active ingredients. ${ }^{14}$ There are very little literature availability on plant materials as active ingredients in herbal medicines i.e. Ayurveda and Unani medicines and less scientific data regarding the identity and effectiveness of these herbal products. In current times, several researchers identifying new drugs and provide significant formulations from different medicinal plants and those drugs are also precursors for synthesis new bioactive molecules for treating various diseases including liver diseases. ${ }^{15-18}$ However, there were ample of medicinal plants available on world without their identification and scientifically not proven about their medicinal uses. 
Saponaria officinalis is one of such medicinal plant commonly called as soapwort plant belongs to Caryophyllaceae family. The different parts of $S$. officinalis has been used in traditional medicine, roots as blood purifier, diuretic, diaphoretic; roots and leaves for scrofula and skin diseases; sap for scabies, hepatic eruptions, to increase bile flow. ${ }^{19}$ But, there were no scientific reports on hepatoprotective activity of root parts of $S$. officinalis. In this regards, the present work carried out to evaluate the phytochemical analysis and hepatoprotective activity of $S$. officinalis.

\section{MATERIALS AND METHODS}

\section{Chemicals and Drugs}

All the chemical used in the present study were analytical grade. Diagnostic kits for serum parameter analysis were purchased from Span diagnostics Ltd, Gujarat, India. Paracetamol tablets and Live 52 was purchased from local medical shop, Visakhapatnam, A.P, India.

\section{Preparation of extracts}

The plant materials Saponaria officinalis (Voucher number: 1221) were collected from Tirupati region, Andhra Pradesh and authenticated by the taxonomist Dr. K. Madhava Chetty, Depart of Botany, Sri Venkateswara University. Freshly collected roots of plant material were shade dried and then material was milled to obtain a coarse powder. The powdered material was successively extracted with ethyl acetate, chloroform and methanol using in a Soxhlet apparatus. Finally, collected solutions were concentrated to dryness under vacuum by using Rota-vapor and stored in desiccators.

\section{Phytochemical analysis}

Phytochemical studies were carried out for different extracts of Saponaria officinalis to identify the presence of different phytochemical constituents using standard procedures..$^{20-23}$

\section{Total phenolic content estimation}

Total phenolic content was estimated using folin-ciocalteau reagent. Briefly, folin-ciocalteau colorimetry is based on a chemical reduction of the reagent, a mixture of tungsten and molybdenum oxides. The products of the metal oxide reduction have a blue absorption with a maximum at $765 \mathrm{~nm}$. The intensity of the light absorption at that wave length is proportional to the concentration of phenols. By using standard Gallic acid calibration curve, measure the concentration of phenolic content in Gallic acid total equivalents using unit's mg/gm. (GAE).22,24

\section{Total alkaloid content estimation}

The plant extract $(1 \mathrm{mg} / \mathrm{mL})$ was dissolved in $2 \mathrm{~N} \mathrm{HCl}$ and then filtered. The $\mathrm{pH}$ of phosphate buffer solution was adjusted to neutral with $0.1 \mathrm{~N}$ $\mathrm{NaOH}$. One $\mathrm{ml}$ of this solution was transferred to a separating funnel and then $5 \mathrm{ml}$ of Bromocresol green (BCG) solution along with $5 \mathrm{ml}$ of phosphate buffer were added. The mixture was shaken and the complex formed was extracted with chloroform by vigorous shaking. The extracts were collected in a $10 \mathrm{~mL}$ volumetric flask and diluted to volume with chloroform. The absorbance of the complex in chloroform was measured at $470 \mathrm{~nm}$. All experiments were performed thrice; the results were averaged and reported in the form of Mean \pm S.E.M..$^{22,25}$

\section{Selection of Animals}

Albino rats of either sex weighing between 180-250 gm were obtained from M/s. Mahaveer Enterprises, Hyderabad, India. The animals were maintained under controlled environmental conditions (temperature of $22 \pm 1^{\circ} \mathrm{C}$ ) with an alternating $12 \mathrm{~h}$ light-dark cycle and relative humidity of $60 \pm 5 \%$ ), one week before the start and also during the experimental period. They were fed up with standard laboratory diet and water ad libitum during experimental period. Food was withdrawn $12 \mathrm{~h}$ before the terminating experiment and water was allowed ad libitum. The protocols were approved by Institutional Animal Ethics Committee and the lab was approved by CPCSEA, Government of India (Regd. No. 516/01/A/ CPCSEA).

\section{Acute toxicity studies}

The acute toxicity study was conducted for extracts of $S$. officinalis extracts as per OECD guidelines 420 and regulations. ${ }^{26}$ The albino rats of single sex, were selected and divided into three groups $(n=6)$. They were maintained for one week before the experiment, under room temperature and allowed free access to water and diet. The animals were subjected for acute toxicity study using each extract at a dose of $2000 \mathrm{mg} / \mathrm{kg}$ orally in 3 groups at regular intervals of time for $24 \mathrm{~h}$. During this period, animals were under examination to note different conditions like skin changes, morbidity, aggressiveness, oral secretions, sensitivity to sound and pain, respiratory movements and finally their mortality.

\section{Evaluation of hepatoprotective activity using Paracetamol-induced hepatotoxicity}

Hepatoprotective activity of the $S$. officinalis extracts were carried out by using Paracetamol-induced hepatotoxicity in rats. ${ }^{27}$ The animals for the activity, selected animals were divided into twelve groups (XII; $n=6$ ). Group I was served as control treated with only Saline $(2 \mathrm{~mL} / \mathrm{kg}$ b.w., per orally) for one week. Group II was administered with saline solution $(2 \mathrm{~mL} / \mathrm{kg}$ b.w., per orally) for 7 days. The animals of group III were administered with Liv 52 (25mg/kg per day, p. o.) for 7 days. Group IV to XII animals were administered with ethyl acetate, chloroform and methanol extracts of $S$. officinalis (125, 250 and $500 \mathrm{mg} / \mathrm{kg}$ respectively) for 7 days. On 5th day for all groups excluding group I were treated with paracetamol $(200 \mathrm{mg} / \mathrm{kg}$ b. w., s.c. $)$. On $7^{\text {th }}$ day after dosage of $2 \mathrm{~h}$, the groups were anaesthetized by chloroform and blood was collected from retro-orbital plexus. The collected samples were centrifuged using centrifuge at $2400 \mathrm{rpm}$ for $15 \mathrm{~min}$ and then serum was clearly separated. The collected serum was analyzed for biochemical parameters i.e. AST (SGOT), ALT (SGPT), ALP, total bilirubin and total protein levels using Autoanalyzer. ${ }^{27}$

\section{Statistical analysis}

All the results were expressed as mean \pm SEM and analysed by using Two-way ANOVA followed by Dunnet's multiple comparision test. All groups were compared with Liv 52 group. ${ }^{* *} p<0.001$; ${ }^{* *} p<0.01$; ${ }^{*} p<0.05$; $\mathrm{ns}=$ Non significance.

\section{RESULTS}

\section{Phytochemical analysis}

Qualitative phytochemical screening of S. officinalis extracts revealed the presence of different phytochemical constituents like steroids, terpenoids, flavonoids, alkaloids, glycosides, phenols, tannins and carbohydrates. All the extracts revealed the presence of phenols, alkaloids, steroids and glycosides, tannins and gave negative results to amino acids, quinones and oils. The ethyl acetate and methanol extracts revealed the presence of saponins, flavanoids but the chloroform extract gave negative results. The chloroform and methanol extracts revealed the presence of carbohydrates, but ethyl acetate extract gave negative results (Table 1). The quantified phenolic content of $S$. officinalis extracts was ranging from $17.52 \pm 0.46$ to $22.51 \pm 1.05$ (mg/gm). The methanol extract has more phenolic content $35.47 \pm 0.42(\mathrm{mg} / \mathrm{gm})$ than other extracts and alkaloid content was ranging from $18.43 \pm 0.74$ to $22.64 \pm 0.78$ (mg/gm). The ethyl acetate extract has more alkaloid content $22.64 \pm 0.78(\mathrm{mg} / \mathrm{gm})$ than other extracts (Table 2). 
Table 1: Nature of phytoconstituents in different extracts of Saponaria officinalis.

\begin{tabular}{cccc}
\hline \multirow{2}{*}{ Name of the } & \multicolumn{3}{c}{ Extracts of Saponaria officinalis } \\
\cline { 2 - 4 } Phytochemicals & Chloroform & Ethyl Acetate & Methanol \\
\hline Phytosterols & + & + & + \\
Terpenoids & + & + & + \\
Glycosides & + & + & + \\
Saponins & - & + & + \\
Flavonoids & - & + & + \\
Tannins & + & + & + \\
Carbohydrates & + & - & + \\
Alkaloids & + & + & + \\
Amino acids & - & - & - \\
Oils & - & - & - \\
Quinones & - & - & - \\
Phenols & + & + & + \\
\hline
\end{tabular}

$+=$ Present, $-=$ Absent

Table 2: Total phenolic and alkaloid contents (mg/gm) of Saponaria officinalis extracts.

\begin{tabular}{ccc} 
Name of the extract & $\begin{array}{c}\text { Total Phenolic } \\
\text { content }(\mathrm{mg} / \mathrm{gm}) \\
(\text { Mean } \pm \text { SEM) }\end{array}$ & $\begin{array}{c}\text { Total alkaloidal content } \\
\text { (mg/gm) } \\
(\text { Mean } \pm \text { SEM) }\end{array}$ \\
\hline Ethyl acetate & $21.59 \pm 0.17$ & $22.64 \pm 0.78$ \\
Chloroform & $17.52 \pm 0.46$ & $18.43 \pm 0.74$ \\
Methanol & $22.51 \pm 1.05$ & $20.58 \pm 0.59$ \\
\hline
\end{tabular}

\section{Acute toxicity studies}

The S. officinalis root extracts were found to be safe after the toxicity test dose of $2000 \mathrm{mg} / \mathrm{kg}$ administration, because there were no sign of mortality and no behavioral changes were observed in rats.

\section{Hepatoprotective activity}

S. officinalis root extracts (ethyl acetate, chloroform and methanol) were evaluated for their hepatoprotective activity on Paracetamol-induced liver toxicity in rats at different concentrations $(125 \mathrm{mg} / \mathrm{kg}$ b.w, $250 \mathrm{mg} /$ $\mathrm{kg}$ b.w and $500 \mathrm{mg} / \mathrm{kg} \mathrm{b.w}$ ) and found concentration dependent percentage protection based on SGOT, SGPT, ALP, Total serum bilirubin and Total protein levels on end of experiment (Table 3, Figure 1, 2 and 3).

The control group which was given normal saline did not showed any significant changes but Group II which is treated with normal saline and paracetamol on $5^{\text {th }}$ day showed significant changes compared to group I, The animals of group III was induced with paracetamol and was treated Liv 52 (Positive) showed the significant restoration of altered biomarker enzymes with percentage protection $94.79 \%, 92.97 \%, 96.49 \%, 97.57 \%$ and $90.24 \%$ of liver (AST (SGOT), ALT (SGPT), ALP, total bilirubin and total protein) levels.

The percentage protection of ethyl acetate extract of $S$. officinalis (SOEAE) at $125 \mathrm{mg} / \mathrm{kg}, 250 \mathrm{mg} / \mathrm{kg}$ and $500 \mathrm{mg} / \mathrm{kg}$ b.w on AST (SGOT), ALT (SGPT), ALP, total bilirubin and total protein levels at were 9.95\%, $7.81 \%, 9.00 \% 9.55 \%$ and $8.54 \%, 21.19 \%, 19.84 \%, 24.49 \%, 20.83 \%$ and $19.51 \%, 41.77 \%, 37.97 \%, 45.96 \%, 38.19 \%$ and $40.24 \%$.

The percentage protection produced by the chloroform extract of S. officinalis (SOCE) on AST (SGOT), ALT (SGPT), ALP, total bilirubin
Table 3: Enzymes Levels of groups I to XII animals due to the effect of different extracts of $S$. officinalis.

\begin{tabular}{cccccc}
\hline \multirow{2}{*}{ Name of the } & \multicolumn{5}{c}{ Name of Enzymes } \\
\cline { 2 - 6 } Drug & AST & ALT & ALP & T. bil & T. ptn \\
& (U/L) & (U/L) & (U/L) & (mg/dl) & (gm/dl) \\
\hline Control & $89.17 \pm$ & $52.33 \pm$ & $183.50 \pm$ & $0.25 \pm$ & $6.93 \pm$ \\
& 1.11 & 1.73 & 0.85 & 0.01 & 0.06 \\
Paracetamol & $332.17 \pm$ & $173 \pm$ & $548.67 \pm$ & $2.17 \pm$ & $4.20 \pm$ \\
& 2.18 & 5.22 & 21.60 & 0.06 & 0.04 \\
Liv 52 25mg// & $101.83 \pm$ & $59.83 \pm$ & $195.67 \pm$ & $0.29 \pm$ & $6.67 \pm$ \\
kg b. w. & 1.72 & 1.11 & 1.56 & 0.01 & 0.08 \\
SOEAE 125mg/ & 308.00 & 150.67 & 498.67 & 1.98 & 4.43 \\
kg b.w & \pm 0.82 & \pm 0.76 & \pm 1.36 & \pm 0.05 & \pm 0.08 \\
SOEAE 250mg/ & 280.67 & 137.83 & 445.00 & 1.77 & 4.73 \\
kg b.w & \pm 1.94 & \pm 0.87 & \pm 1.46 & \pm 0.06 & \pm 0.04 \\
SOEAE 500mg/ & 230.67 & 118.50 & 370.67 & 1.43 & 5.30 \\
kg b.w & \pm 1.09 & \pm 0.96 & \pm 1.09 & \pm 0.06 & \pm 0.09 \\
SOCE & 292.83 & 142.50 & 470.33 & 1.87 & 4.60 \\
125mg/kg b.w & \pm 2.34 & \pm 1.06 & \pm 1.45 & \pm 0.07 & \pm 0.05 \\
SOCE 250mg/ & 254.83 & 125.83 & 409.50 & 1.57 & 5.03 \\
kg b.w & \pm 2.26 & \pm 1.89 & \pm 3.01 & \pm 0.06 & \pm 0.06 \\
SOCE 500mg/ & 195.67 & 100.83 & 316.67 & 1.07 & 5.67 \\
kg b.w & \pm 1.17 & \pm 2.10 & \pm 3.12 & \pm 0.04 & \pm 0.07 \\
SOME & 277.17 & 137.67 & 445.00 & 1.77 & 4.77 \\
125 mg/kg b.w & \pm 2.51 & \pm 0.49 & \pm 1.44 & \pm 0.06 & \pm 0.06 \\
SOME 250mg/ & 234.00 & 116.50 & 375.83 & 1.37 & 5.27 \\
kg b.w & \pm 2.42 & \pm 1.96 & \pm 1.78 & \pm 0.06 & \pm 0.04 \\
SOME 500mg/ & 170.17 & 94.33 & 301.50 & 0.93 & 5.87 \\
kg b.w & \pm 0.91 & \pm 1.78 & \pm 1.67 & \pm 0.07 & \pm 0.04 \\
\hline
\end{tabular}

$\mathrm{n}=6$ and Mean $\pm \mathrm{SD}$

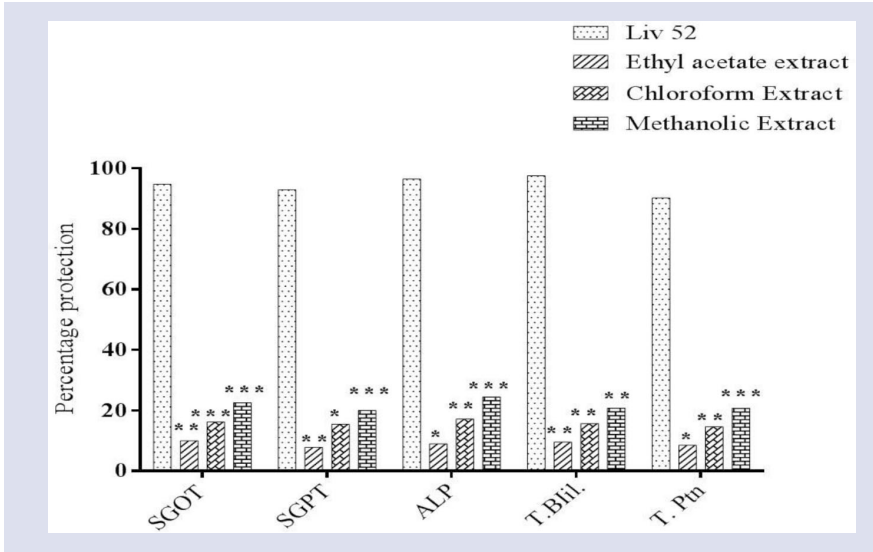

Figure 1: Percentage protection produced by different extracts of S. officinalis at a dose of $125 \mathrm{mg} / \mathrm{kg}$.

Results were analysed by using Two-way ANOVA followed by Dunnet's multiple comparision test. All gropus were compared with Liv 52 group. ${ }^{* * *} p<0.001 ;{ }^{* *} p<0.01 ;{ }^{*} p<0.05 ; \mathrm{ns}=$ Non significance $(n=6)$, T.Bil= Total Bilirubin; T.Ptn= Total Protein. 


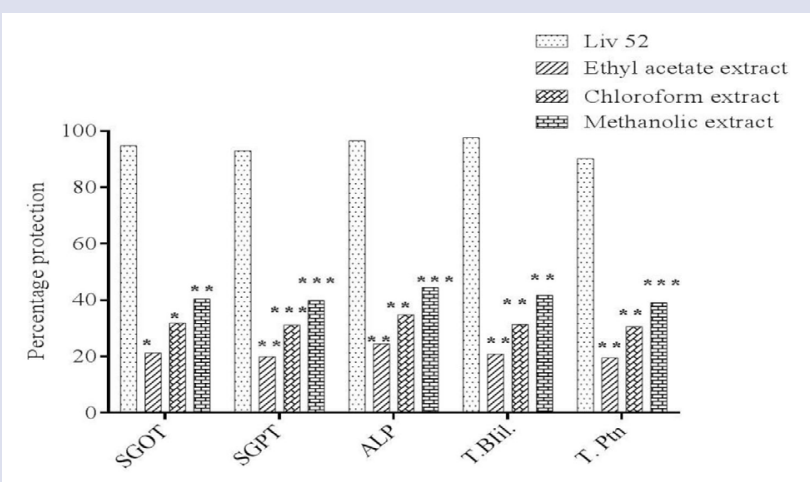

Figure 2: Percentage protection produced by different extracts of S. officinalis at a dose of $250 \mathrm{mg} / \mathbf{k g}$.

Results were analysed by using Two-way ANOVA followed by Dunnet's multiple comparision test. All gropus were compared with Liv 52 group. ${ }^{* * *} p<0.001 ;{ }^{* *} p<0.01 ;{ }^{*} p<0.05$; ns $=$ Non significance $(n=6)$, T.Bil= Total Bilirubin; T.Ptn= Total Protein.

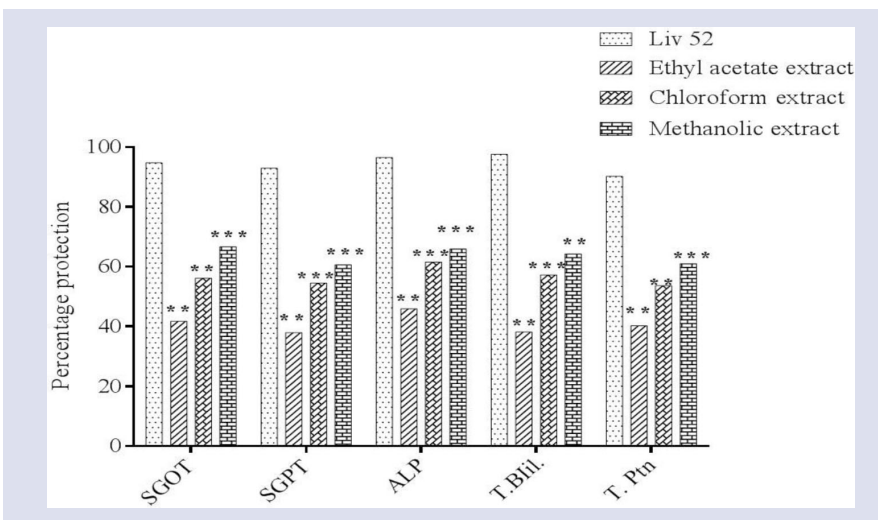

Figure 3: Percentage protection produced by different extracts of S. officinalis at a dose of $500 \mathrm{mg} / \mathbf{k g}$.

Results were analysed by using Two-way ANOVA followed by Dunnet's multiple comparision test. All gropus were compared with Liv 52 group. ${ }^{* * *} p<0.001 ;{ }^{* *} p<0.01 ;{ }^{*} p<0.05 ;$ ns $=$ Non significance $(\mathrm{N}=6), \mathrm{T} . \mathrm{Bil}=$ Total Bilirubin; T.Ptn= Total Protein.

and total protein levels were $16.19 \%, 15.47 \%, 17.18 \%, 15.63 \%$ and $14.63 \%$, $31.82 \%, 31.09 \%$, $34.74 \% 31.25 \%$ and $30.49 \%$, 56.17\%, $54.53 \%$, $61.55 \% 57.29 \%$ and $53.66 \%$ respectively.

The percentage protection produced by the methanol extract of S. officinalis (SOME) on AST (SGOT), ALT (SGPT), ALP, total bilirubin and total protein levels were $22.63 \%, 20.00 \%, 24.49 \%, 20.83 \%$ and $20.73 \%, 40.40 \%, 39.84 \%, 44.47 \%, 41.67 \%$ and $39.02 \%, 66.67 \%, 60.63 \%$, $65.93 \%, 64.24 \%$ and $60.98 \%$ respectively.

\section{DISCUSSION}

The studies on natural products and isolation of new drugs from them is getting more attention because of currently using drugs are becoming inactive and micro-organisms becoming resistant to them. ${ }^{28-31}$ As mentioned in introduction, S. officinalis one of the traditional medicinal plant with less scientific literature, so the present work carried out on S. officinalis root part for their phytochemical analysis using different extracts and evaluation of hepatoprotective activity. Several studies have been reporting on pharmacological and biological activities of medicinal plants like anti-microbial, ${ }^{32-33}$ antioxidant and hepatoprotective, ${ }^{34-37}$ antiinflammatory, ${ }^{38}$ and cytotoxicity etc.
The phytochemical analysis of different extracts of S. officinalis root part showed presence of bioactive compounds in them and variation in the presence of them in different extracts. All extracts gave positive results for terpenoids, alkaloids, steroids, glycosides and phenols and gave negative results for amino acids, quinones and oils. Methanol and chloroform extracts gave positive results for saponins and flavanoids. Carbohydrates gave positive results for chloroform and methanol extracts, absent in ethyl acetate extract. There were some earlier reports about the presence of biological active compounds in S. officinalis, quillaic acid from rhizome (root) part, ${ }^{39}$ triterpenoid saponins. ${ }^{40}$

The extracts were analyzed for their hepatoprotective activity because recently drugs induced liver damage causing one of the major mortality problem around the world. ${ }^{41}$ In the present study, the extracts of S. officinalis showed concentration dependent hepatoprotective activity. As the concentration of extracts increasing the protective nature of them was also increased in restoration of the liver biomarker enzymes like SGOT, SGPT, ALP, total bilrubin and total protein. As overall the methanolic extract showed better activity compared to other two extracts (Table 3 ) but individually different extracts showed variation on the enzymes level protection at higher concentrations. Ethyl acetate and chloroform extracts have more percentage protection on ALP levels but methanolic extracts have more protection on AST levels (Figure 3). The protective nature of $S$. officinalis extracts was comparable with standard drug Liv 52. In our earlier studies, we have reported about the antioxidant and antibacterial activities of these extracts. ${ }^{42-43}$ As in those studies, the methanol extract showed more antioxidant and antibacterial activity as hepatoprotective activity in the present study.

In recent decades, different new drugs have been isolating from natural products. ${ }^{44}$ The plants contains wide diversity of chemical constituents in them, but many medicinal plants are still unexplored about their medicinal uses. ${ }^{45}$ The results of present study and previous studies indicating that $S$. officinalis roots possess different bioactive compounds with different biological activities like antioxidant, antibacterial, hepatoprotective and similar to us, antitumor effects, ${ }^{46}$ antimethanogenic effect ${ }^{47}$ and antimethanogenic effect ${ }^{48}$ of $S$. officinalis was reported. However, the results obtained in present study are warrant for further studies on different medicinal plants used as food and in traditional medicine.

\section{CONCLUSION}

The present research reveal that $S$. officinalis roots contains different phytochemical constituents and those extracts possess hepatoprotective activity and in our earlier research work we found these also possess antibacterial and antioxidant activities. The liver damage will occur mainly due to the over production of free radical and S. officinalis roots showed free radicals inhibition. So, it may conclude that common biological active components of them were responsible for their activities either individually or synergistically. So, further work is needed to isolate and characterize the responsible bioactive molecules from these extracts as well as from different medicinal plants for development of effective and safe medicines.

\section{ACKNOWLEDGMENT}

The authors thankful to RGNF fellowship, UGC for their financial support, authorities of AU College of Pharmaceutical Sciences, Andhra University for providing the necessary facilities to complete present work.

\section{CONFLICT OF INTEREST}

The authors declare no conflict of interest. 


\section{ABBREVIATIONS}

GAE: Gallic acid total equivalents; BCG: Bromocresol green; OECD: Organisation for Economic Co-operation and Development; AST (SGOT): Aspartate aminotransferase; ALT (SGPT): Alanine aminotransferase; ALP: Alkaline phosphatase.

\section{REFERENCES}

1. Abdullatif A, Ahmad N, Abed NA. Anti-Inflammatory Activity of Natural Products. Molecules. 2016;21:1321.

2. Dossing M, Sonne J. Drug induced hepatic disorders: Incidence, management and avoidance. Drug Safety. 1993;9(6):441-9

3. Mukesh S, Majumdar PK. Occupational lifestyle diseases: An emerging issue. Indian J Occup Environ Med. 2009;13(3):109-12.

4. Grant LM, Rickey DC. Drug-inudced liver injury. Curr Opin Gastroenterol. 2012;28:198-202.

5. Murray KF. Drug-related hepatotoxicity and acute liver failure. J Pediatr Gastroenterol Nutr. 2008;47(4):395-405.

6. Reuben A, Koch DG, Lee WM. Acute liver failure (ALF) secondary to drug induced liver injury (DILI): Causes and consequences. Hepatology. 2009;50: 347A.

7. Björnsson E. Review article: drug-induced liver injury in clinical practice. Aliment Pharmacol Ther. 2010;32(1):3-13.

8. Hirschfield GM, Thain C, Walmsley M, Brownlee A, Jones DE. Liver disease in the UK. Lancet. 2015;385(9967):503.

9. Raúl JA, Aida OA, María IL. Drug-Induced Liver Injury Clinical Consortia: a global research response for a worldwide health challenge. Expert Opinion on Drug Metabolism and Toxicology. 2016;12(6):589-93.

10. Chu J, Sadler KC. New school in liver development: Lessons from zebrafish. Hepatology. 2009;50(5):1656-63.

11. Bramstedt K. Living liver donor mortality: where do we stand?. Am J Gastroenterol. 2006;101(4):755-9.

12. Talwani R, Gilliam BL, Howell C. Infectious diseases and the liver. Clin Liver Dis. 2011;15(1):111-30

13. Porceddu M, Buron N, Roussel C, Labbe G, Fromenty B, Borgne-Sanchez A Prediction of liver injury induced by chemicals in human with a multiparametric assay on isolated mouse liver mitochondria. Toxicol Sci. 2012;129(2):332-45.

14. Gupta SS. Prospects and perspectives of natural plant products in medicine. Indian J Pharmacol. 1994;26(1):1-12.

15. Hong M, Li S, Tan HY, Wang N, Tsao SW, Feng Y. Current Status of Herbal Medicines in Chronic Liver Disease Therapy: The Biological Effects, Molecular Targets and Future Prospects. Int J Mol Sci. 2015;16(12):28705-45.

16. Khokhlenkova NV, Kovalenko SM, Azarenko JM, Buryak MV. Development of methodical approaches to the creation of the pharmacologically active bandage. Asian J Pharm Clin Res. 2017;10:20-4.

17. Lodha R, Bagga A. Traditional Indian systems of medicine. Ann Acad Med Singap. 2000;29(1):37-41.

18. Subbarayappa BV. The roots of ancient medicine: an historical outline. J BioSs 2001;26(2):135-43.

19. Khare CP. Indian Medicinal Plants: An Illustrated Dictionary. Springer. 2007.

20. Ayoola GA, Coker HAB, Adesegun SA, Adepoju-Bello AA, Obaweya K, et al. Phytochemical screening and antioxidant activities of some selected medicinal plants used for malaria therapy in Southwestern Nigeria. Trop J Pharm Res. 2008;7(3):1019-24

21. Prashant T, Bimlesh K, Mandeep K, Gurpreet K, Harleen K. Phytochemical screening and extraction: A review. Int Pharm Sci. 2011;1(1):98-106.

22. Rao BG, Rao YV, Rao TM. Hepatoprotective and antioxidant capacity of Melochia corchorifolia extracts. Asian Pac J Trop Med. 2013;6(7):537-43.

23. Trease G, Evans SM. Pharmacognosy. $15^{\text {th }}$ ed. Bailer Tindal, London, Elsevier Publisher. 2002;23-67.

24. Singleton VL, Rossi JA. Colorimetry of total phenolics with phosphomolybdic acid phosphotungstic acid reagents. Am J Enol Vitic. 1965;16(3):144-58.
25. Fazel S, Hamidreza M, Rouhollah G, Verdian-rizi M. Spectrophotometric determination of total alkaloids in some Iranian medicinal plants. TJPS. 2008;32:17-20.

26. Organisation for Economic Co-operation and Development. Acute Oral ToxicityFixed Dose. 2001

27. Ramachandra SS, Quereshi AA, Viswanath SAH, Patil T, Prakash T, Prabhu K. Hepatoprotective activity of Calotropis procera flowers against paracetamolinduced hepatic injury in rats. Fitoterapia. 2007;78(7-8):451-4.

28. Hiroshi N. Multidrug Resistance in Bacteria. Annu Rev Biochem. 2009;78:119-46.

29. Molinari G. Natural products in drug discovery: present status and perspectives. Adv Exp Med Biol. 2009;655:13-27.

30. Mouhssen L. The Success of Natural Products in Drug Discovery. Pharmacology and Pharmacy. 2013;4(3A):17-31.

31. Xiaoyun S, Kosten RT. Immunotherapy for Drug Abuse. CNS Neurol Disord Drug Targets. 2011;10(8):876-9.

32. Anyanwu MU, Okoye RC. Antimicrobial activity of Nigerian medicinal plants J Intercult Ethnopharmacol. 2017;6(2):240-59.

33. Silva NCC, Fernandes JA. Biological properties of medicinal plants: a review of their antimicrobial activity. The Journal of Venomous Animals and Toxins Including Tropical Diseases. 2010;16(3):402-13.

34. Eduardo MS, Eduardo MB, Isela ÁG, María TSM, José GS, Mirandeli B, et al. Review of natural products with hepatoprotective effects. World J Gastroenterol 2014;20(40):14787-804.

35. Ilyas U, Deepshikha PK, Vidhu A, Punnooth PN. A Review on Hepatoprotective and Immunomodulatory Herbal Plants. Pharmacogn Rev. 2016;10(19):66-70.

36. Majid AS, Najme KF, Nafiseh A, Ali F, Ebrahim AA, Mahmoud RK. Medicinal plants with hepatoprotective activity in Iranian folk medicine. Asian Pac J Trop Biomed. 2015;5(2):146-57.

37. Qadir MI, Ahmad Z. Advances in hepatoprotective medicinal plants research Bangladesh J Pharmacol. 2017;12(3):229-42

38. Abdul LA, Ahmad N, Abed NA. Anti-Inflammatory Activity of Natural Products. Molecules 2016;21(10):1321

39. Henry M, Brion JD, Guignard JL. A propos des saponines de la Saponaire officinale. Plant Med Phytol. 1981;15:192-200.

40. Jia Z, Koike K, Nnikaido T. Major Triterpenoid Saponins from Saponaria officinalis J Nat Prod. 1998;61(11):1368-73.

41. Marcellin P, Kutala BK. Liver diseases: A major, neglected global public health problem requiring urgent actions and large-scale screening. Liver Int 2018;38(Suppl. 1):2-6.

42. Veda PG, Mallikarjuna RT, Ganga RB. Oxidative stress inhibitory aptitude of Saponaria officinalis and Zanthoxyllum aramatum. International Journal of Science and Nature. 2017;8(1):75-80

43. Veda PG, Mallikarjuna RT, Ganga RB. Antibacterial activity of Saponaria officinalis and Zanthoxyllum aramatum. International Journal of Pharmacology and Toxicology. 2017;5(1):1-4

44. Sharma GK. Studies on Phytochemical Constituents of Medicinal Plants. AJPPS. 2014:1(4):61-74

45. Iabal A, Mabood HF, Maheshwari M, Zahin M. Medicinal Plants and Phytocompounds: A Potential Source of Novel Antibiofilm Agents. Antibiofilm Agents 2014;8:205-32.

46. Thorpe PE, Brown AN, Bremner JAJ, Foxwell BM, Stirpe F. An immunotoxin composed of monoclonal anti-thy 1.1 antibody and a ribosome-inactivating protein from Saponaria officinalis: potent antitumor effects in vitro and in vivo. J Natl Cancer Inst. 1985;75(1):151-9.

47. Lu Y, Van D, Deibert L, Bishop G, Balsevich J. Antiproliferative quillaic acid and gypsogenin saponins from Saponaria officinalis Roots. Phytochemistry. 2015;113:108-20.

48. Cieslak A, Zmora P, Stochmal A, Pecio L, Oleszek W, Pers-Kamczyc E, et al. Rumen antimethanogenic effect of Saponaria officinalis $L$. phytochemicals in vitro. J Agric Sci. 2014;152(6):981-93.

Cite this article:Talluri MR, Gummadi VP, Battu GR. Chemical Composition and Hepatoprotective Activity of Saponaria officinalis on Paracetamol-induced Liver Toxicity in Rats. Pharmacog J. 2018;10(6)Suppl:s129-s134. 


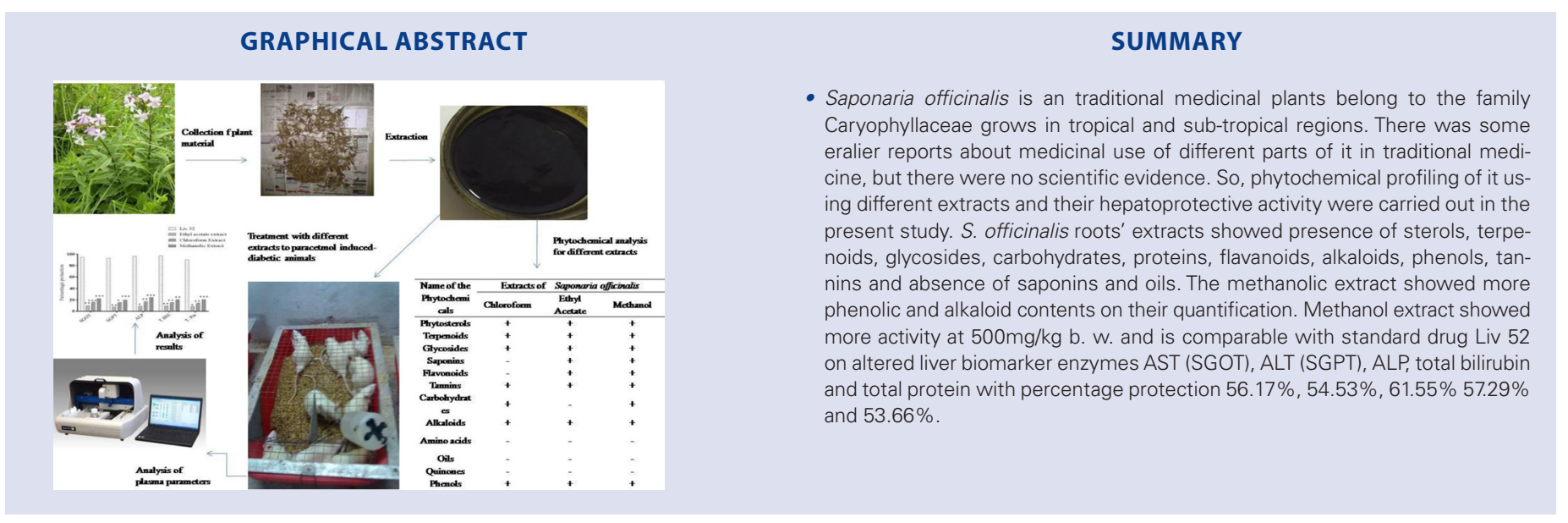

